\title{
A Comparative Study to Assess the Preoperative Thickness of Lateral Trochanteric Wall as a Predictor of Postoperative Lateral Wall Fracture in Intertrochanteric Fracture Treated by Dynamic Hip Screw
}

\author{
Sreejith KP ${ }^{1}$, Jyothiprasanth $\mathbf{M}^{2}$ and Nithin Sunku ${ }^{3 *}$ \\ ${ }^{1}$ Consultant Orthopaedic Surgeon, District Hospital, Calicut, Kerala, India \\ ${ }^{2}$ Consultant Orthopaedic Surgeon, Kuttyadi Taluk Hospital, Calicut, Kerala, India \\ ${ }^{3}$ Consultant Orthopaedic Surgeon, AKG Hospital Kannur, Kerala, India
}

${ }^{*}$ Corresponding author: Nithin Sunku, Consultant Orthopaedic Surgeon, AKG Hospital Kannur, Kerala, India, Tel: +91-9886389529; E-mail: drsnithin@gmail.com

Received date: Aug 11, 2017, Accepted date: Aug 24, 2017, Published date: Aug 29, 2017

Copyright: (C) 2017 Sreejith KP, et al. This is an open-access article distributed under the terms of the Creative Commons Attribution License, which permits unrestricted use, distribution, and reproduction in any medium, provided the original author and source are credited.

\section{Abstract}

The aim of this study was to assess the preoperative thickness lateral trochanteric wall as a predictor of postoperative lateral wall fracture in intertrochanteric fracture treated by dynamic hip screw fixation. A Radiograph based Comparative study involved 66 patients with intertrochanteric fracture treated by dynamic hip screw fixation.

All patients had an intact lateral wall preoperatively and were AO/OTA $31 \mathrm{~A} 1$ and AO/OTA $31 \mathrm{~A} 2$ fractures [1]. Mean age of the patients was 75 years. All patients were followed up with $\mathrm{x}$-ray at 1 month and 6 months postoperatively. Age, gender, side of fracture, type of fracture as per AO/OTA classification, the pre-operative thickness of the lateral trochanteric wall, the tip-apex distance and the status of the trochanteric wall after 6 months from surgery were subjected to analysis [2]. Radiographs were retrieved from the Picture Archive and Communication System and thickness of the lateral wall calculated. Measurements were corrected for magnification using the radiological magnification factor. Of the 66 patients, a fracture of the lateral wall occurred in 26 patients (39.39\%). The lateral was intact in 40 patients $(60.61 \%)$. The mean pre-operative thickness of the lateral wall of the 26 patients with a lateral wall fracture was $17.8 \mathrm{~mm}$ (SD-6.45) compared to $26.9 \mathrm{~mm}$ (SD-6.93) in 40 patients without a lateral wall fracture.

The mean thickness of trochanteric wall in 39 patients with $\mathrm{A} 1$ fracture was $27.5 \mathrm{~mm}(\mathrm{SD}=7.17)$ whereas the mean thickness in A2 type fracture (27 cases) was 17.3 $\mathrm{mm}(\mathrm{SD}=4.88) .74 .07 \%$ of patients with $\mathrm{A} 2$ type fracture developed a fracture of the lateral wall whereas only $15.38 \%$ of $A 1$ type fracture had a fracture of lateral wall after a six months follow-up. Factors like age at the time of operation, gender, side of fracture, tip-apex distance (if less than $25 \mathrm{~mm}$ ) has no significant relation with development of post-operative lateral wall fracture.
In summary, when the lateral wall thickness is less than $20.55 \mathrm{~mm}$ there is significantly high chance of lateral wall getting fractured if fixed with a DHS alone.

Keywords: Intertrochanteric fracture; Lateral wall thickness; DHS; Radiological magnification factor; AO/OTA

\section{Materials and Methods}

\section{Study design}

A comparative study to assess the preoperative thickness of lateral trochanteric wall as a predictor of postoperative lateral wall fracture in intertrochanteric fracture treated by dynamic hip screw. It is essentially a radiograph based study.

\section{Study area}

The study was conducted at the Department of Orthopedics, Ernakulam Medical Centre, Palarivattom, Kochi, Kerala.

This is a super specialty hospital with more than 350 beds, with a separate trauma division along with other subspecialties. It has a well-equipped Physical Medicine department with dedicated full time physiotherapist.

\section{Study population}

Patients with Intertrochanteric fractures admitted to department of Orthopaedic Surgery, Ernakulam Medical Centre, Kochi.

Sixty-six patients who were admitted and operated for intertrochanteric fracture, at our hospital between the period of January 2009 to November 2013 satisfying the inclusion criteria. 


\section{Inclusion criteria}

\section{Intertrochanteric fractures with:}

- AO type 31 A1 and 31 A2

- Fixation using DHS alone

- Preoperatively intact lateral wall

- Exclusion criteria

- Non traumatic fractures

- Pre-operative or intra-operative fracture of the lateral wall

- Deep seated surgical site infections

- Patients with previous fractures in trochanteric region

- Fixation other than DHS

- Poor reduction

- Tip-apex distance more than $25 \mathrm{~mm}$

- Follow-up period less than 6 months

- Associated fractures in the ipsilateral femur

\section{Data collection technique and tools:}

Primary: Using Hospital Medical Records

- X-RAYS taken at the time of admission, in the postoperative period and during the follow-up visits.

- npatient case sheet written by the doctors

- Operation notes

- Operation theatre registers

- Outpatient notes

The parameters that were recorded initially included the age, gender, side of fracture, type of fracture as per AO/OTA classification system. Only AO/OTA 31 A1 and 31 A2 were selected for the study.

Fracture fixation was done in a conventional manner on a fracture-table under fluoroscopic control. Only DHS was done. Medical co-morbidities were addressed simultaneously.

All the patients were mobilized partial weight bearing using walker support from the second or third post-operative day onwards. In all the patients, the post-operative rehabilitation was done under the guidance of a physiotherapist.

Patients were reviewed with Antero-posterior and lateral radiographs at 1 month, 2 month and 6 months postoperatively.

The digitalized $x$-rays which included the Antero-posterior (AP) and lateral views of the pre-operative, immediate postoperative and the $1^{\text {st }}$ and 6 month follow-up of the selected patients were then retrieved from the Picture Archive and Communication System.

Failure of treatment was defined as

- Penetration of the screw into the hip joint

- Loosening within the femoral head

- Implant failure in the form of breakage of the barrel-plate or its screws

- These X-rays were then assessed for:

- Adequacy of reduction
- Status of the lateral trochanteric wall.

- The Tip-apex distance.

- The type of fracture according to the AO/OTA classification system.

Poor fracture reduction was defined as more than $20^{\circ}$ angulation at the fracture site on the lateral radiograph, and $>4 \mathrm{~mm}$ of displacement of any fragment.

The Tip-apex distance was calculated as per Baumgaertner method (Figure 1). (Tip-apex distance is the sum of the distance from the tip of the screw to the apex of the femoral head on Antero-posterior (AP) and lateral radiographs, after correcting for the radiological magnification).

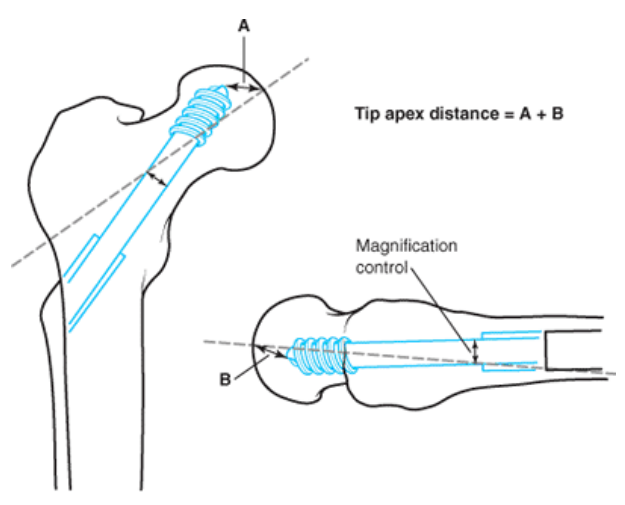

Figure 1: Tip-apex distance

\section{Calculation of thickness of lateral trochanteric wall}

Thickness of lateral trochanteric wall was measured on the Antero-posterior view of the preoperative x-ray (Figure 2).

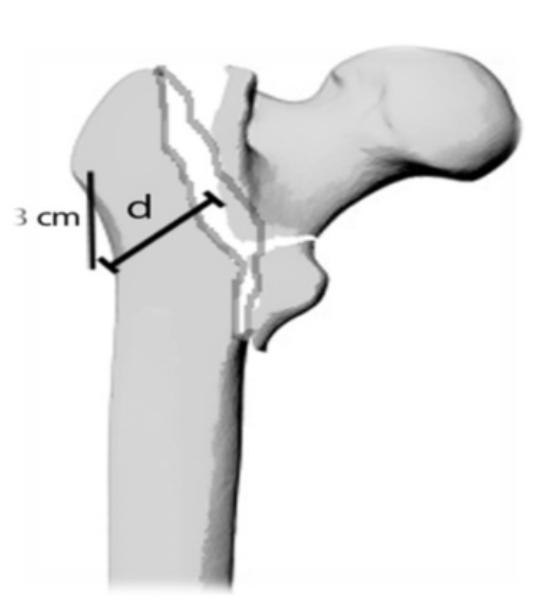

Figure 2: Lateral wall thickness

A fixed point on the lateral wall was identified $3 \mathrm{~cm}$ below the innominate tubercle of the greater trochanter. From this fixed point, angled at 135 degree upwards to the fracture line (midway between two cortical lines) is defined as the thickness of the trochanteric wall. 
The midway between the two cortical lines is taken as the reference point to compensate for the variable rotation of the distal fragment.

Lateral wall thickness is defined as the distance in $\mathrm{mm}$ from a reference point $3 \mathrm{~cm}$ below the innominate tubercle of the greater trochanter, angled at $135^{\circ}$ upward to the fracture line (the midline between the two cortex lines) on Antero-posterior radiograph (Figure $\mathbf{3}$ ).

The measurements taken were then corrected by the radiological magnification factor.

The radiological magnification factor was calculated by the formula:

Magnification factor $=\frac{S I D}{S O D}$

$S I D=D i s t a n c e$ from the source to image (detector).

SOD=Distance from the source to object.

Actual size of the object $=\frac{\text { Size of the image }}{\text { Magnification factor }}$
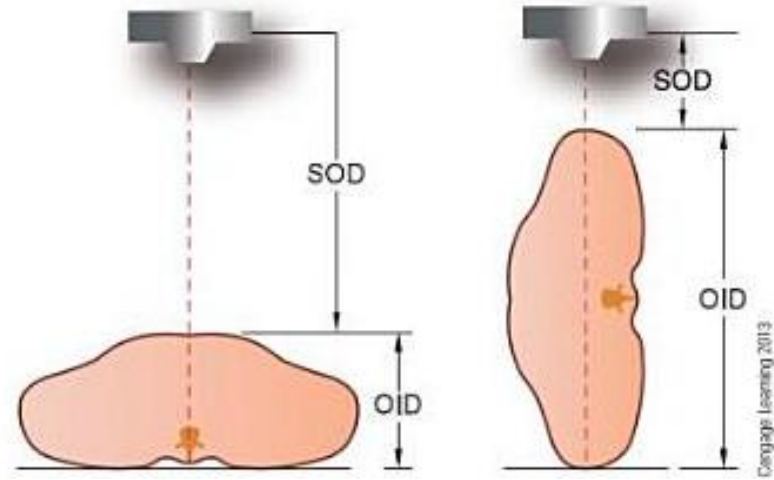

Figure 3: Lateral wall fracture. SOD=Source to object; OID=Object to image (detector): SID=Source to image.

The $1^{\text {st }}$ and $6^{\text {th }}$ month follow-up x-rays were assessed for any fracture of the lateral wall.

Lateral wall fracture was defined as the presence of any new fracture line occurring at the site of insertion of the barrel plate or any lateral displacement of the fracture fragment on the radiograph.

Following factors were subjected for statistical analysis:

- Age at the time of operation

- Gender

- Side of fracture

- Tip apex distance

- Type of fracture as per AO/OTA classification system

- Thickness of lateral trochanteric wall

- Post-operative status of lateral wall

\section{Statistical analysis and results}

This study was conducted in 66 patients with intertrochanteric fracture who had undergone DHS fixation at department of orthopaedics, Ernakulam Medical Centre, Kochi during the period from January 2009 to November 2013. All the sixty-six patients had presented to the emergency department with pain over the hip. 58 of them presented following a trivial fall at their home. 6 patients were brought with fall at work area while 2 suffered from a road accident.

All the patients after optimization were operated under spinal anaesthesia. All patients had undergone a fracture reduction by indirect method on a fracture table and dynamic hip screw fixation. DHS alone was done.

The post-operative rehabilitation protocol was same in all the patients. Patients were allowed touchdown weight bearing and walking with help of a walker support in the second or third post-operative day. All the wounds healed without any signs of infection and the skin sutures were removed at appropriate time. In all the patients, an X-ray to assess the fixation and to get a baseline was taken on the second or third post-operative day.

In all the patients, the follow-up X-rays which included Antero-posterior and lateral views were taken at 1 month and 6 month post-operatively.

Age, gender, side of fracture, type of fracture as per AO/OTA classification, the pre-operative thickness of the lateral trochanteric wall, the tip-apex distance and the status of the trochanteric wall after 6 months from surgery were subjected to analysis.

There were 21 males (31.8\%) and 45 females (68.2\%) in the study. The mean age at operation was 74 (SD-10.72) years.

\section{Comparison for age}

Table 1: Distribution of Age. NS $\rightarrow$ Not significant; comparable

\begin{tabular}{|c|c|c|c|c|}
\hline & \multicolumn{2}{|c|}{ Lateral Wall Fracture } & \multirow{2}{*}{$\begin{array}{l}\text { Total } \\
(\mathrm{N}=66)\end{array}$} & \multirow[b]{2}{*}{ p - value } \\
\hline & $\begin{array}{l}\text { No } \\
\text { Fracture } \\
(\mathrm{N}=40)\end{array}$ & $\begin{array}{l}\text { Fracture } \\
(\mathrm{N}=26)\end{array}$ & & \\
\hline Age (Mean \pm SD) & $\begin{array}{l}75.3 \\
10.64\end{array}$ & $\begin{array}{l}72 \\
10.75\end{array}$ & $\begin{array}{ll}74 & \pm \\
10.72\end{array}$ & $0.225^{\mathrm{NS}}$ \\
\hline
\end{tabular}

Of the patients who sustained a post-operative lateral wall fracture, the mean age was 72 years (SD- 10.75) compared with 75.3 years (SD-10.64) in patients without a fracture (Figure 4). The age was insignificant in development of postoperative lateral wall fracture (Table 1$)$. (P value=0.225) 


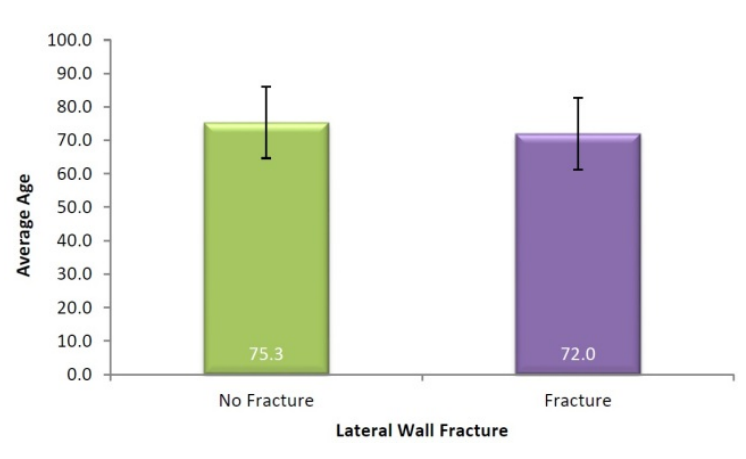

Figure 4: Distribution of age.

\section{Comparison for side of fracture}

Of the total study population, right side was involved in 37 patients $(56.06 \%)$ and left in 29 patients (43.94\%).

Of the 37 patients with right sided fracture, 17 patients (45.9\%) developed a post-operative lateral wall fracture and out of the 29 left sided fractures, 9(31\%) developed postoperative lateral wall fracture (Figure 5).

Table 2: Distribution of Side. NS $\rightarrow$ Not significant; comparable.

\begin{tabular}{|c|c|c|c|c|}
\hline \multirow[b]{2}{*}{ Side } & \multicolumn{2}{|c|}{ Lateral Wall Fracture } & \multirow{2}{*}{$\begin{array}{l}\text { Total } \\
(\mathrm{N}=66)\end{array}$} & \multirow[b]{2}{*}{$p$ - value } \\
\hline & $\begin{array}{l}\text { No } \\
\text { Fracture } \\
(\mathrm{N}=40)\end{array}$ & $\begin{array}{l}\text { Fracture } \\
(\mathrm{N}=26)\end{array}$ & & \\
\hline Right & $20(54.1)$ & $17(45.9)$ & 37 & \multirow{2}{*}{$0.219 \mathrm{NS}$} \\
\hline Left & $20(69)$ & $9(31)$ & 29 & \\
\hline
\end{tabular}

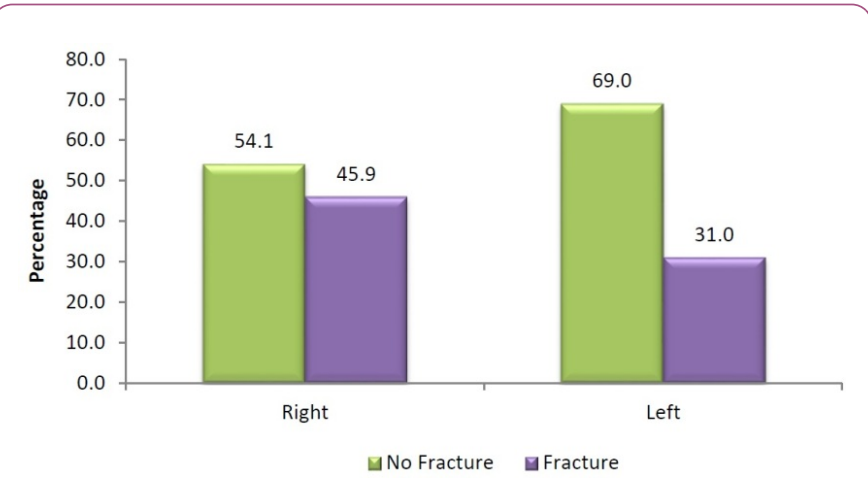

Figure 5: Distribution of side.

Side of intertrochanteric fracture was not found to be significantly related to development of post-operative lateral wall fracture (Table 2). ( $p$ value 0.219)

\section{Comparison for gender}

Females formed the majority of the study population-45 patients $(68.18 \%)$ compared to males-21 patients $(31.81 \%)$.
Of the 21 males, 11 patients (52.4\%) sustained a lateral wall fracture and the remaining 10 patients (47.6\%) had an intact lateral wall (Table 3).

29 of the 45 female patients, i.e. $64.4 \%$ developed postoperative lateral wall fracture whereas in 16 patients (35.6\%), the lateral wall was intact (Figure 6). ( $P$-value=0.350)

The gender of the patient and the incidence of postoperative lateral wall fracture has no significant relation ( $p$ value $=0.350$ )

Table 3: Distribution of gender. NS $\rightarrow$ Not significant; compara.

\begin{tabular}{|c|c|c|c|c|}
\hline \multirow{2}{*}{ Gender } & \multicolumn{2}{|c|}{ Lateral Wall Fracture } & \multirow{2}{*}{$\begin{array}{l}\text { Total } \\
(\mathrm{N}=66)\end{array}$} & \multirow[b]{2}{*}{$p-$ value } \\
\hline & $\begin{array}{l}\text { No } \\
\text { Fracture } \\
(\mathrm{N}=40)\end{array}$ & $\begin{array}{l}\text { Fracture } \\
(\mathrm{N}=26)\end{array}$ & & \\
\hline Male & $11(52.4)$ & $10(47.6)$ & 21 & \multirow{2}{*}{$0.350 \mathrm{NS}$} \\
\hline Female & $29(64.4)$ & $16(35.6)$ & 45 & \\
\hline
\end{tabular}

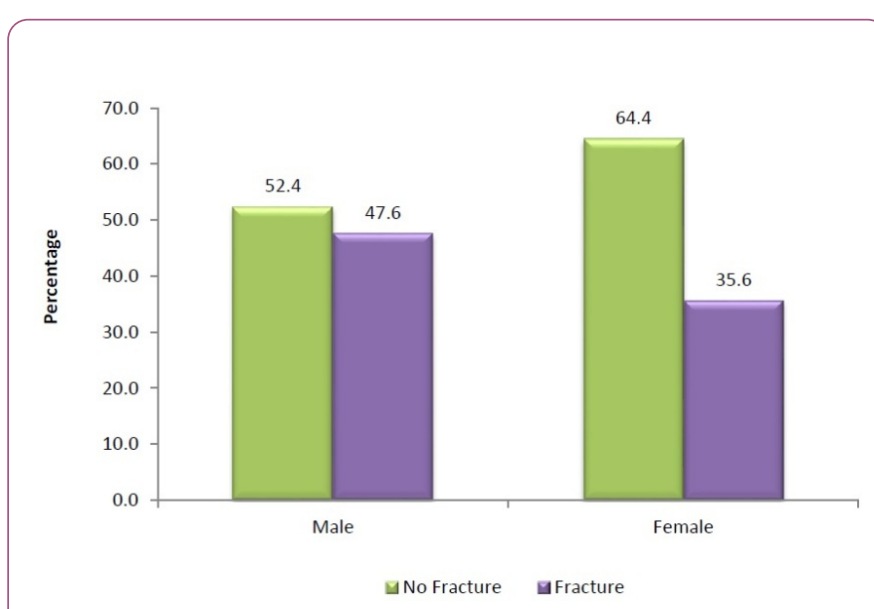

Figure 6: Distribution of gender.

\section{Comparison of type of fracture}

The classification system followed in this study was the AO/OTA classification for proximal femoral fractures. The subtype of this classification was not followed because of wide inter observer variability.

Only AO/OTA type $31 \mathrm{~A} 1$ and type $31 \mathrm{~A} 2$ were included in the study.

There were a total 39 patients with AO/OTA type 31 A1 fracture and 27 patients with AO/OTA type 31A2 fracture.

Of the A1 type fracture, 6 patients (15.4\%) developed a post-operative fracture of the lateral wall. 33 patients (84.6\%) of $A 1$ fracture had their lateral wall intact after 6 months of follow-up.

Of the A2 type fracture, 20 patients (74.1\%) developed fracture of lateral wall whereas only 7 patients $(35.9 \%)$ had an intact lateral wall at the end of 6 months (Table 4). 
This shows that the incidence of lateral wall fracture in the post-operative period is significantly more in AO/OTA type A2 fractures than in AO/OTA A1 type fractures (Figure 7). ( $P$ value $=0.000$ ).

Table 4: Distribution of Type of fracture. ${ }^{* *}$ Significant at 0.01 level.

\begin{tabular}{|l|l|l|l|l|}
\hline \multirow{2}{*}{$\begin{array}{l}\text { AO/OTA } \\
\text { Type }\end{array}$} & \multicolumn{2}{|c|}{ Lateral Wall Fracture } & \multicolumn{1}{|c|}{$\begin{array}{l}\text { Total } \\
(\mathrm{N}=66)\end{array}$} & \multirow{2}{*}{$\mathbf{p}$ - value } \\
\cline { 2 - 4 } & $\begin{array}{l}\text { No } \\
\text { Fracture } \\
(\mathrm{N}=40)\end{array}$ & $\begin{array}{l}\text { Fracture } \\
(\mathrm{N}=26)\end{array}$ & \multicolumn{2}{|c}{$0.000^{* *}$} \\
\hline A1 & $33(84.6)$ & $6(15.4)$ & 39 & \\
\hline A2 & $7(25.9)$ & $20(74.1)$ & 27 & \\
\hline
\end{tabular}

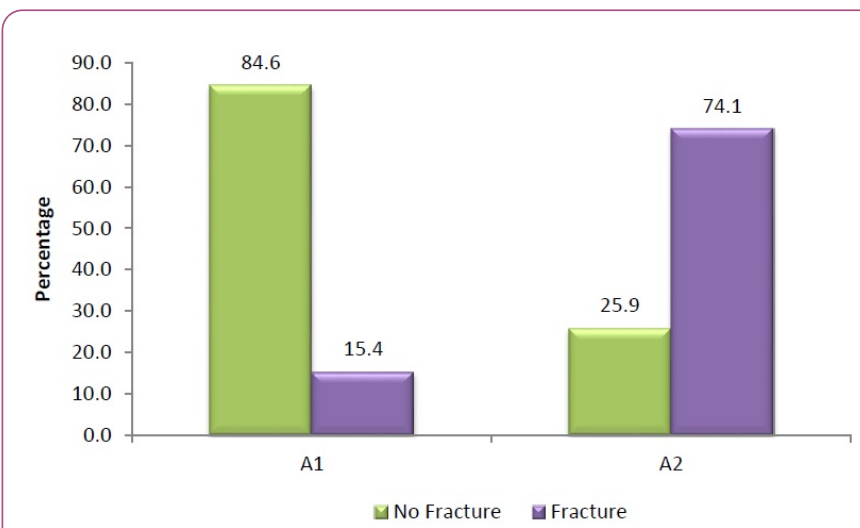

Figure 7: Distribution of type of fracture.

\section{Comparison of tip-apex distance}

Table 5: Distribution of tip-apex distance (TAD). NS $\rightarrow$ Not significant; comparable.

\begin{tabular}{|c|c|c|c|c|}
\hline & \multicolumn{2}{|c|}{ Lateral Wall Fracture } & $\begin{array}{l}\text { Total } \\
(\mathrm{N}=66)\end{array}$ & \multirow[b]{2}{*}{$p$-value } \\
\hline & $\begin{array}{l}\text { No } \\
\text { Fracture } \\
(\mathrm{N}=40)\end{array}$ & $\begin{array}{l}\text { Fracture } \\
(\mathrm{N}=26)\end{array}$ & & \\
\hline TAD $($ Mean $\pm S D)$ & $\begin{array}{l}19.2 \\
3.26\end{array}$ & $\begin{array}{l}20.5 \\
2.66\end{array}$ & $\begin{array}{l}19.7 \\
3.09\end{array}$ & $0.097 \mathrm{NS}$ \\
\hline
\end{tabular}

Only those DHS fixation with a tip apex distance less than 25 $\mathrm{mm}$ were included in the study. The mean TAD of the study population was $19.7 \mathrm{~mm}(S D=3.09)$. In the group with postoperative lateral wall fracture, the mean TAD was $20.5 \mathrm{~mm}$ $(S D=2.66)$. In those fracture without a post-operative lateral wall fracture, the mean TAD was $19.2 \mathrm{~mm}(\mathrm{SD}=3.26)$ (Figure 8).

The TAD if less than $25 \mathrm{~mm}$ was found to be insignificant ( $p$ value $=0.097$ ) with incidence of post-operative lateral wall fracture (Table 5).

\section{Comparison of lateral wall thickness}

Of the 66 patients, a fracture of the lateral wall occurred in 26 patients (39.39\%). The lateral was intact in 40 patients (60.61\%). The mean pre-operative thickness of the lateral wall of the 26 patients with a lateral wall fracture was $17.8 \mathrm{~mm}$ (SD-6.45) compared to $26.9 \mathrm{~mm}$ (SD-6.93) in 40 patients without a lateral wall fracture (Figure 9). This shows that the incidence of lateral wall fracture was more in thin lateral wall compared with those with a thick lateral wall (Table 6).

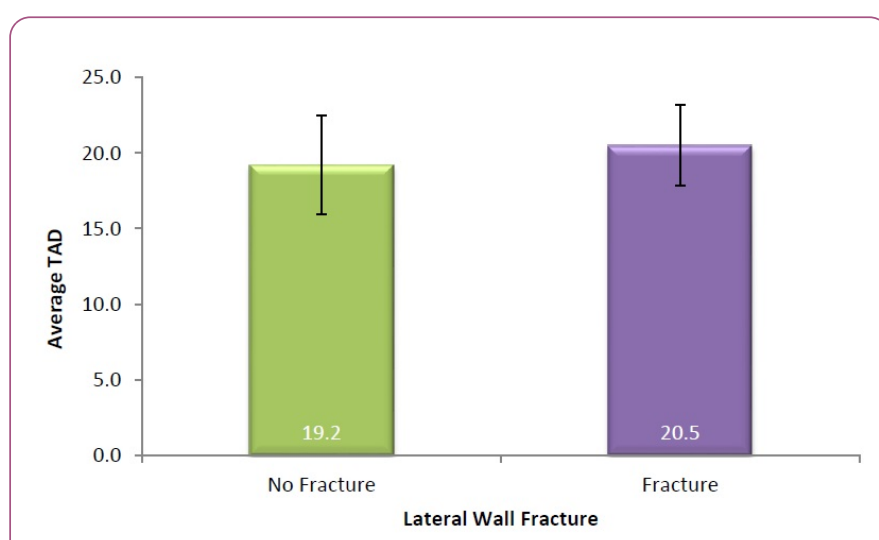

Figure 8: Distribution of TAD.

Table 6: Distribution of thickness. NS $\rightarrow$ Not significant, $* *$ Significant at 0.01 level.

\begin{tabular}{|c|c|c|c|c|}
\hline \multirow[b]{2}{*}{ Type } & \multicolumn{2}{|c|}{ Lateral Wall Fracture } & $\begin{array}{l}\text { Total } \\
(\mathrm{N}=66)\end{array}$ & \multirow[b]{2}{*}{$p$ - value } \\
\hline & $\begin{array}{l}\text { No } \\
(\mathrm{N}=40)\end{array}$ & $\begin{array}{l}\text { Fracture } \\
(\mathrm{N}=26)\end{array}$ & & \\
\hline A1 & $28.1 \pm 6.49$ & $24.1 \pm 10.26$ & $\begin{array}{l}27.5 \quad \pm \\
7.17\end{array}$ & $0.218 \mathrm{NS}$ \\
\hline $\mathrm{A} 2$ & $21.3 \pm 6.59$ & $15.9 \pm 3.29$ & $\begin{array}{l}17.3 \quad \pm \\
4.88\end{array}$ & $0.009^{\star *}$ \\
\hline Total & $26.9 \pm 6.93$ & $17.8 \pm 6.45$ & $\begin{array}{l}23.3 \quad \pm \\
8.05\end{array}$ & $0.000^{* *}$ \\
\hline
\end{tabular}

An ROC curve (Figure 10) was used to estimate a threshold value of thickness that could predict lateral wall fracture (Table 7). The Receiver Operating Characteristic curve showing the sensitivity against the 100 - specificity was plotted. The area under the curve was 0.852 . (95\% confidence interval 0.748 to 0.956)

The AUC measures the ability of the lateral wall thickness to classify correctly the patients with and without a high risk of post-operative lateral wall fracture. The best cut-off point for balancing sensitivity and specificity was found to be $20.55 \mathrm{~mm}$. When lateral wall thickness was at $20.55 \mathrm{~mm}$, the sensitivity was $85.0 \%$ and specificity was $88.5 \%$. The area under the curve (AUC) was 0.852 , which was statistically significant $(p<0.001)$.

This shows that when the pre-operative lateral wall thickness is less than $20.55 \mathrm{~mm}$, there is high chance of postoperative lateral wall fracture when fixed with DHS alone. 


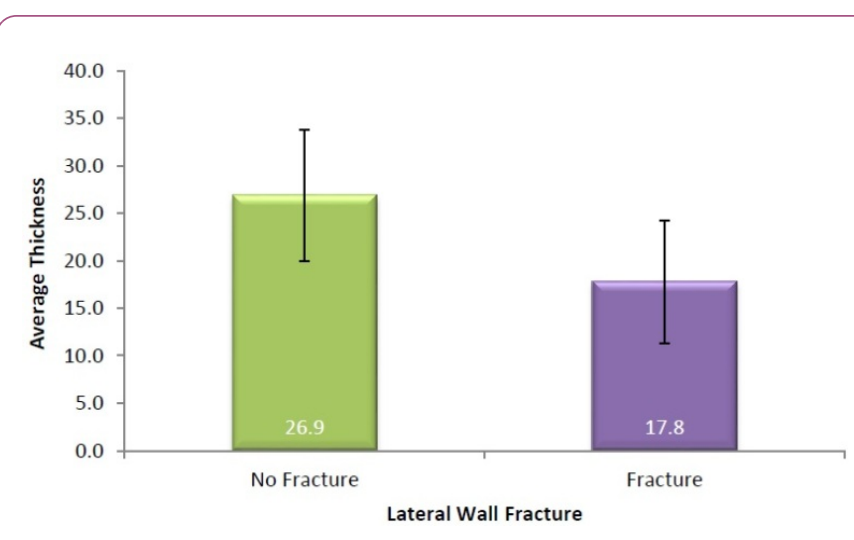

Figure 9: Distribution of thickness.

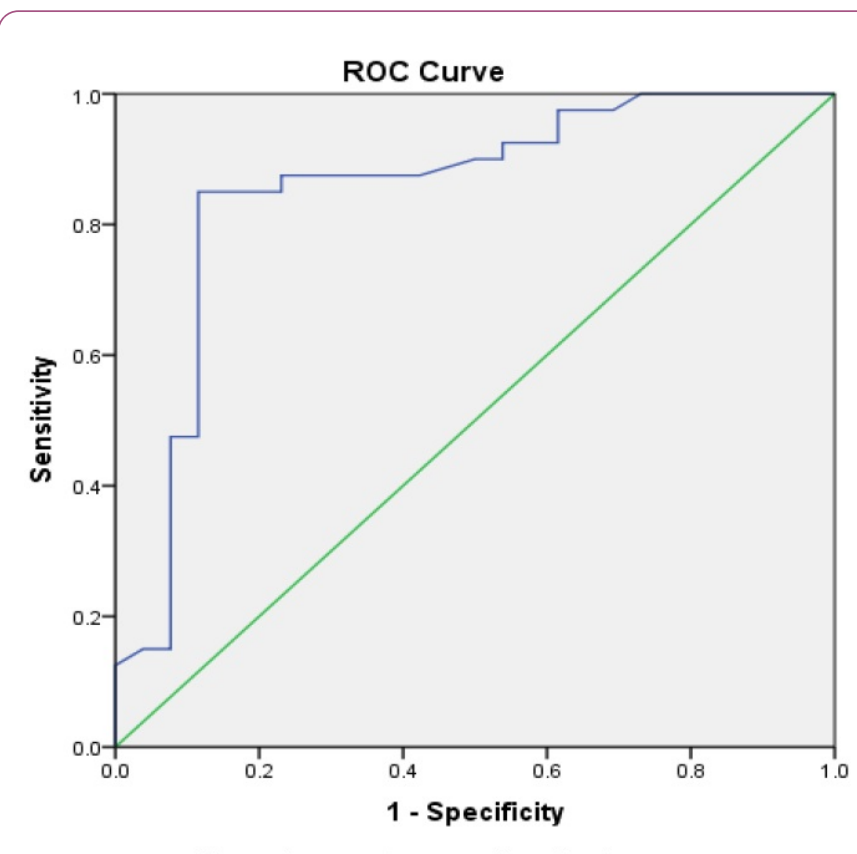

Diagonal segments are produced by ties.

Figure 10: ROC curve

Table 7: Estimation of threshold value of thickness

\begin{tabular}{|l|l|}
\hline Area under Curve & $0.852(0.748-0.956)$ \\
\hline Sensitivity & 85 \\
\hline 100 - Specificity & 88.5 \\
\hline Cut point & 20.55 \\
\hline
\end{tabular}

\section{Comparison of thickness against type of fracture}

Table 8: Distribution of Thickness against type of fracture. NS $\rightarrow$ Not significant, $* *$ Significant at 0.01 level.

\begin{tabular}{|c|l|l|l|}
\hline Type & Lateral Wall Fracture & $\begin{array}{l}\text { Total } \\
(\mathrm{N}=66)\end{array}$ & $\mathrm{p}$ - value \\
\hline
\end{tabular}

\begin{tabular}{|c|c|c|c|c|}
\hline & $\begin{array}{l}\text { No } \\
\text { Fracture } \\
(\mathrm{N}=40)\end{array}$ & $\begin{array}{l}\text { Fracture } \\
(\mathrm{N}=26)\end{array}$ & & \\
\hline A1 (39) & $\begin{array}{l}28.1 \\
6.49\end{array}$ & $\begin{array}{l}24.1 \\
10.26\end{array}$ & $\begin{array}{l}27.5 \\
7.17\end{array}$ & $0.218 \mathrm{NS}$ \\
\hline A2 (27) & $\begin{array}{l}21.3 \\
6.59\end{array}$ & $\begin{array}{l}15.9 \\
3.29\end{array}$ & $\begin{array}{l}17.3 \quad \pm \\
4.88\end{array}$ & $0.009^{* *}$ \\
\hline Total (66) & $\begin{array}{l}26.9 \\
6.93\end{array}$ & $\begin{array}{l}17.8 \\
6.45\end{array}$ & $\begin{array}{l}23.3 \quad \pm \\
8.05\end{array}$ & $0.000^{* *}$ \\
\hline
\end{tabular}

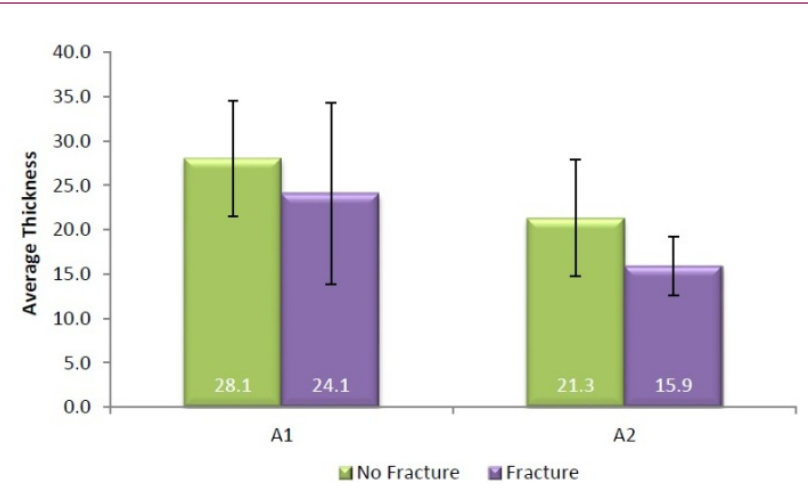

Figure 11: Distribution of type.

The mean thickness of trochanteric wall in 39 patients with A1 fracture was $27.5 \mathrm{~mm}(\mathrm{SD}=7.17)$ whereas the mean thickness in $A 2$ type fracture (27 cases) was $17.3 \mathrm{~mm}$ $(S D=4.88)$. The thickness in $A 1$ fractures was significantly smaller than that in A2 type fractures (Table 8).

Of the patients with a post operatively fractured lateral wall, 6 patients belonged to $A 1$ group. 20 patients with a fractured lateral wall had an initial A2 type fracture.

$74.07 \%$ of patients with A2 type fracture developed a fracture of the lateral wall whereas only $15.38 \%$ of A1 type fracture had a fracture of lateral wall after a six months followup. This shows the incidence of lateral wall getting fractured was significantly high in A2 type fractures ( $p$ value 0.000 ) compared to $A 1$ type fractures.

Of $A 2$ fractures, the mean lateral wall thickness of 7 patients without lateral wall fracture was $21.3 \mathrm{~mm}$ (SD=6.59), which was significantly greater than $15.9 \mathrm{~mm}(S D=3.29)$ in 20 patients with lateral wall fracture. ( $p$ value-0.009) (Figure 11).

\section{Discussion}

Surgical treatment for intertrochanteric fracture has been in practice since decades [3]. Today, Dynamic hip screw is the time tested implant of choice for stable intertrochanteric fractures. Postero-medial cortical continuity is the main criteria described for the stability of these fractures [4]. Those fractures with a comminuted postero-medial wall are unstable [5]. It was only recently; the importance of the presence of an intact lateral trochanteric wall is being recognized. In fractures internally fixed with a DHS, the lateral wall provides a buttress 
on the outer side preventing the fracture from excessive collapse [6].

Gotfried Y [7] in 2004 had reported that, presence of the lateral wall on the preoperative radiograph should be a major factor in determining the internal fixation device used for fracture stabilization. The presence of an intact lateral wall is especially important in fractures with an already comminuted postero-medial wall. It has been seen that mere presence of lateral wall does not prevent excessive collapse in all case. Certain fractures with initial intact lateral wall develop lateral wall fracture in the postoperative period. It has been reported to occur in about $21 \%$ of fractures fixed with DHS alone. Studies shows that these patients with post-operative lateral wall fracture after fixation with DHS, experience a protracted healing period and excessive shortening. Henrik Palm et al. in his study [8] in 2007 reported that preoperative or postoperative fracture of the lateral femoral wall is the main predictor for a reoperation after an intertrochanteric fracture treated by DHS (Figure 12).

It is therefore necessary to find out pre-operatively which ITF are likely to develop fracture in the lateral wall in the postoperative period. Understanding this will help us to select the correct implant and method of fixation necessary [9].

Palm H, Jacobsen $\mathrm{S}$ et al. in their study in 2007 revealed that lateral wall fracture occurs more frequently in AO/OTA 31-A2.2 and 31-A2.3 than in 31-A1 and 31-A2.1 fractures.

C-E. Hsu, C-M. Shih, C-C. Wang, K-C. Huang from Taichung Veterans General Hospital, Taiwan [10] conducted a retrospective study to identify the pre-operative thickness of the lateral wall as a predictor of post-operative lateral wall fracture. They concluded that pre-operative thickness is a reliable predictor and intertrochanteric fractures with lateral wall thickness less than $20.5 \mathrm{~mm}$ are likely to develop postoperative lateral wall fractures. According to them these fractures should not be fixed with DHS alone (Figure 13).

This study with 66 intertrochanteric fractures fixed with DHS alone, shows that the mean thickness of lateral wall in patients with post-operative lateral wall fracture was only $17.8 \mathrm{~mm}$ (SD-6.45) compared to $26.9 \mathrm{~mm}$ (SD-6.93) in patients without a lateral wall fracture.

Using an ROC curve to estimate a threshold value that could predict lateral wall fractures the best cut-off point for balancing sensitivity and specificity was found to be $20.55 \mathrm{~mm}$. It was seen that the sensitivity was 85.0 and specificity 88.50 when the lateral wall thickness was at $20.55 \mathrm{~mm}$. This shows that when the pre-operative thickness of lateral wall was less than $20.55 \mathrm{~mm}$ the chance of post-operative lateral wall fracture is very high when fixed with DHS alone (Figure 14).

It was also noted that $84.6 \%$ of type $31 \mathrm{~A} 1$ fractures had their lateral wall intact after 6 months follow-up whereas 74.1\% of type 31 A2 fracture developed a post-operative lateral wall fracture (Figure 15). This shows that the incidence of lateral wall fracture in the post-operative period is significantly more in OA/OTA type A2 fractures than in AO/OTA A1 type fractures. (P-value $=0.000)$.
Factors like age at the time of operation, gender, side of fracture, tip-apex distance (if less than $25 \mathrm{~mm}$ ) has no significant relation with development of post-operative lateral wall fracture.

- There were several limitations in this study.

- The operations were not performed by a single surgeon. The operative skills of surgeons may have been different and,

- This could have affected the treatment outcome.

- The lateral wall fractures were only evaluated by radiography. Linear fractures of lateral wall unseen by $x$-ray could have been missed.

- The sample size was relatively small.

- Different patients may have different bone quality. The Bone Mineral Density was not taken into consideration.

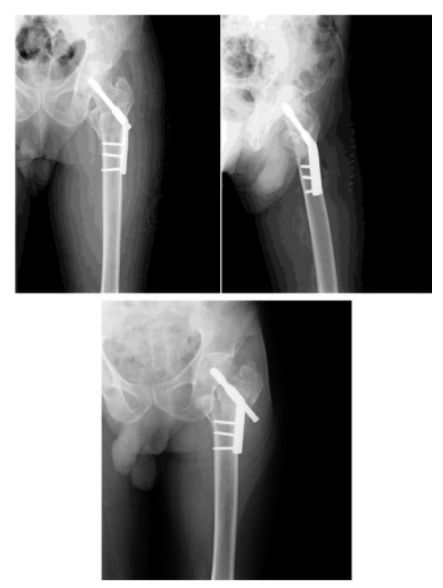

Figure 12: Patient with initial intact but thin lateral wall (18.0 mm, A2 type). Sustained fracture in the post-op period.

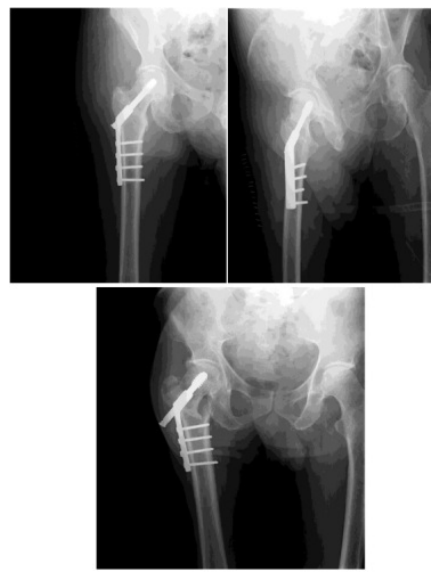

Figure 13: Patient with initial intact but thin lateral wall (14.40 mm, A1 type). Sustained fracture in the post-op period. 

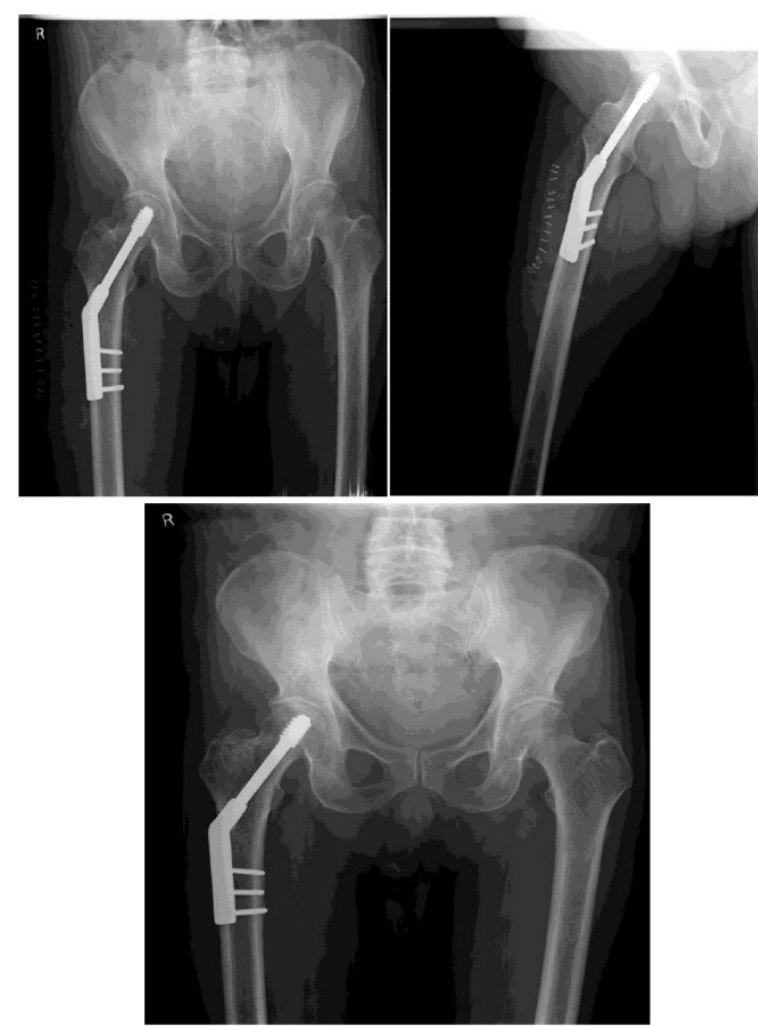

Figure 14: Patient with initial intact thick lateral wall (26.40 $\mathrm{mm}, \mathrm{A} 1$ type). lateral wall intact after 6 months from fixation.
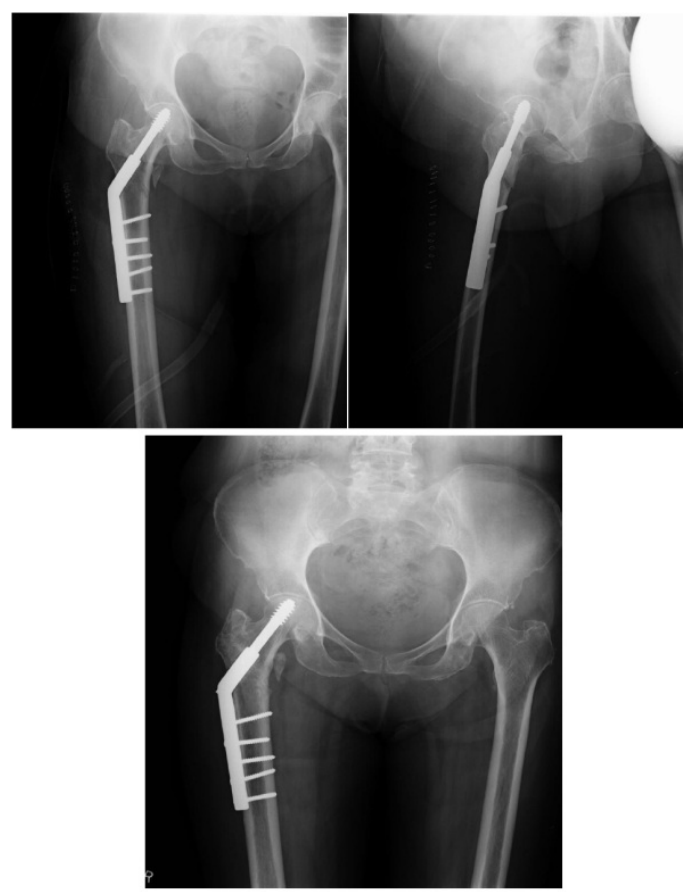

Figure 15: Patient with initial intact thick lateral wall (34.0 $\mathrm{mm}$, type A2). lateral wall intact after 6 months from fixation.

\section{Conclusion}

Intertrochanteric fractures with a post-operative lateral wall fracture following fixation with DHS alone undergo a very protracted healing and other complications of shortening and deformity. It is therefore necessary to prevent the lateral wall from getting fractured at the time of surgery and also identify the risk factors for the lateral wall to get fractured in the postoperative period.

The objective of this study was to assess the pre-operative lateral wall thickness as a predictor for post-operative lateral wall fracture. This study revealed the following findings.

- Preoperative thickness of lateral wall is a reliable predictor for the development of lateral wall fracture in the postoperative period. When the lateral wall thickness is less than $20.55 \mathrm{~mm}$ there is significantly high chance of lateral wall getting fractured if fixed with a DHS alone.

- Intertrochanteric fractures classified as AO/OTA type 31 A2 also has an increased frequency of post-operative lateral wall fracture. Compared to type 31 A1 fractures, 31 A2 fractures has a significantly high risk of lateral wall fracture, following fixation with dynamic hip screw alone.

- Following fixation with DHS in intertrochanteric fracture, factors like age at the time of operation, gender, side of fracture and tip-apex distance(if less than $25 \mathrm{~mm}$ ) has no significant relation with development of post-operative lateral wall fracture.

\section{Recommendations}

Based on this study I would like to make the following recommendations.

- Trochanteric lateral wall is an important structure for the stability of intertrochanteric fracture. Its intactness adds greatly to the stability of the fixation construct.

- Pre-operatively, the thickness of the lateral trochanteric wall has to be assessed and if found to be less than 20.55 $\mathrm{mm}$, DHS in isolation is not an ideal implant for fixation.

- If the thickness of lateral trochanteric wall is less than $20.55 \mathrm{~mm}$, the DHS has to be augmented with a trochanteric support plate or the fixation has to be intramedullary that would support the lateral wall.

- In intertrochanteric fracture with an initial intact lateral wall of adequate thickness, If planning for a dynamic hip screw fixation, great care has to be taken during the surgery so as to not break the lateral wall.

- For AO/OTA classification type 31 A2 fractures, dynamic hip screw alone is not an ideal method of fixation.

\section{References}

1. Boyd HB, Griffin LL (1949) Classification and treatment of intertrochanteric fractures. Arch Surg 58: 853.

2. Baumgaertner MR, Solberg BD (1997) Awareness of tip apex distance reduces failure of fixation of trochanteric fractures. J Bone Joint Surg 79: 969-971. 
3. Cleveland M, Bosworth DM, Thompson FR (1947) Intertrochanteric fractures of the femur: A Survey of Treatment in Tractin and by Internal Fixation. J Bone Joint Surg 29: 1049-1082.

4. Moore, Cram, Parker (2014) Rockwood and Green Fractures in Adults. 2: 4th edn Philedelphia.

5. Boyd HB, Anderson LD (1961) Management of unstable trochanteric fractures. Surg Gynecol Obstet 112: 633.

6. Jacobs RR, Mc Clain O, Armstrong HJ (1980) Internal fixation of intertrochanteric hip fractures. A clinical and biomechanical study. Clin Orthop Relat Res 146: 62-70.

7. Gotfried $Y$ (2004) The lateral trochanteric wall: a key element in the reconstruction of unstable pertrochanteric hip fractures. Clin Orthop Relat Res 425: 82-86.
8. Palm H, Jacobsen S, Sonne-Holm S, Gebuhr P (2007) Integrity of the Lateral Femoral Wall in Intertrochanteric Hip Fractures: an Important Predictor of a reoperation. J Bone Joint Surg Am 89: 470-475.

9. Curtis MJ, Jinnah RH, Wilson V, Cunningham BW (1994) Proximal femoral fractures: a biomechanical study to compare intramedullary and extramedullary fixation. J Bone Joint Surg 25: 99-104.

10. Hsu CE, Shih CM, Wang CC, Huang KC (2013) Lateral femoral wall thickness -A reliable predictor of post-operative lateral wall fracture in intertrochanteric fractures. Bone Joint J 95: 1134-1138. 